\title{
The tendency towards the development of psychosexual disorders in androgenetic alopecia according to the different stages of hair loss: a cross-sectional study*
}

Betul Tas ${ }^{1}$
Hasan Belli
Filiz Kulacaoglu ${ }^{2}$

Murat Altuntas ${ }^{3}$

DOI: http:/ / dx.doi.org/10.1590/abd1806-4841.20185658

\begin{abstract}
BACKGROUND: Androgenetic alopecia is a common dermatological condition affecting both genders.
ОвлестіVЕ: To evaluate the tendency towards development of psychosexual disorders according to the clinical stages of androgenetic alopecia.

Methods: A cross-sectional study was conducted including 353 patients of both sexes on different clinical stages of hair loss, and the patients were enquired about self-perception, self-esteem, sexual experiences, anxiety and depression states. Hair loss was classified by standardized hair loss scales, and psychological effects were assessed with questionnaires. Results were compared to $\mathrm{p}<0.05$.
\end{abstract}

RESULTS: Negative effects on each psychological parameter of androgenetic alopecia in females were higher than in males. While overall comparisons according to hair loss stages for each parameter were significant in males, only sexual experiences, anxiety and depression values were significant in females. Sexual experiences and depression values were higher in Ludwig 3 than in 1\&2, while anxiety was higher in Ludwig 3 than 1. Self-perception values in Norwood 2\&2A were higher than 3A, $3 \mathrm{~V}, 4$ and $4 \mathrm{~A}$, while self-esteem values in $2 \mathrm{~A}$ were higher than $3 \& 4$. Sexual experiences values in 2\&2A were lower than 3, 3A, $3 \mathrm{~V}, 4$ and $4 \mathrm{~A}$, while $3 \& 3 \mathrm{~A}$ were lower than $4 \& 4 \mathrm{~A}$. Depression was lower in $2 \mathrm{~A}$ than $3,3 \mathrm{~A}$, and $3 \mathrm{~V}$, and lower in $2 \mathrm{~A}$ than $4 \mathrm{~A}$. Anxiety was lower in $2 \mathrm{~A}$ than in $4 \& 4 \mathrm{~A}$.

STUDY LIMITATIONS: Relatively small number of patients, who were from a single center.

CONCLUSIONS: In the management of androgenetic alopecia, it should be considered that patients may need psychological support according to the clinical stages, because of increased tendency to develop psychosexual disorders.

Keywords: Alopecia; Anxiety; Depression; Female; Male; Perception; Self concept; Sexual dysfunctions, psychological

\section{INTRODUCTION}

A bidirectional relationship between psychological stress (PS) and certain skin diseases has been well documented. ${ }^{1,2} \mathrm{~Pa}-$ tients with skin diseases often suffer from PS due to the unwanted appearance and subjective symptoms. ${ }^{3}$ Chronic and disfiguring skin diseases may lead to negative impacts on the patients' psychology and their quality of life (QoL), and they may feel stigmatized, anxious or depressed. ${ }^{1,2}$ Hair loss (HL) is a frequent complaint among adults, which mostly leads to cosmetic consequences, however, it can also cause significant psychological and psychosocial impacts. ${ }^{4-7}$ One of the most common causes for HL is androgenetic alopecia(AA), which can affect both sexes. ${ }^{7,8}$ On the other hand, there are very few studies in the literature that evaluated the relationship between HL and its perception by patients. Additionally, the compatibility between the clinical degree of HL and patients' psychological reflections has been very rarely reported. ${ }^{4,5}$ Understanding the effects of the dermatological disorders on psychological states is important to be able to provide comprehensive assistance to patients. Lack of studies regarding the tendency for psychosexual disorders in accordance with the stages of AA in both sexes encouraged us to investigate this relationship.

Received on 04.02.2016.

Approved by the Advisory Board and accepted for publication on 09.01.2017.

* Work performed at the University of Heath Sciences, Istanbul Bagcilar Research and Training Hospital - Istanbul, Turkey. Financial support: None.

Conflict of interest: None.

Department of Dermatology, University of Health Sciences, Istanbul Bagcilar Research and Training Hospital - Istanbul, Turkey. Department of Psychiatry, University of Health Sciences, Istanbul Bagcilar Research and Training Hospital - Istanbul, Turkey. Department of Family Medicine, University of Health Sciences, Istanbul Bagcilar Research and Training Hospital - Istanbul, Turkey.

MAILING ADDRESS:

Betul Tas

E-mail: betulavc@yahoo.com 


\section{METHODS}

Subjects

Appropriate permission for the study was obtained from the Local Ethics Committee of our hospital, with the report Number 2012-92 of 10/12/2012 BEAH/GOKAEK. The study was designed as cross-sectional, clinical research study on AA patients. A total of 353 patients of both sexes (male: 283, female: 70) between the ages of 15-63 with AA, who were admitted to our dermatology outpatient clinic from October 2013 to May 2014, were included in this study. The diagnosis of AA was made according to their dermatological and laboratory examination findings. Patients taking oral corticosteroids, androgenic or psychotropic drugs, or with any androgen-releasing disorders which can lead to alopecia or affect psychological status were excluded from the study. None of the patients had any concomitant dermatological or psychological disorders. The study was based on clinical examination findings and questions about the patients' self-perception (SP), self-esteem (SE), sexual experiences (S-Exp), anxiety (ANX) and depression (DEP) states. The participants were evaluated both by a dermatologist and two psychiatrists. Informed consent was obtained from each patient or their parents before they participated in the study. Sociodemographic information such as the patients' gender and age, educational and marital status, profession, and length of the disease were documented at the beginning of the study. Dermatological examination findings of the patients were recorded using either the female-pattern HL scale of Ludwig or the male-pattern HL scale of Norwood, and they answered questions on previously prepared questionnaires including Self-Perception Scale (SPS), Rosenberg Self-Esteem Scale (RSES), Arizona Sexual Experience Scale (ASEX), Beck Depression Inventory (BDI) and Beck Anxiety Inventory (BAI).

\section{Dermatological and psychological scales \\ Ludwig scale}

The progression of female-pattern baldness (FPAA) is generally classified according to the Ludwig scale, which ranges from stages 1 to 3 . Stage 1 begins with thinning on the top of the head. In stage 2, the scalp starts to show. Finally, almost all of the hair at the crown of the head is lost. ${ }^{8}$

\section{Norwood scale}

The progression of male-pattern baldness (MPAA) is generally classified according to the Norwood scale, which ranges from stages 1 to 7 . Stage 1 is no baldness. Stage 2 shows the adult hairline sitting one finger's width above the upper brow crease, with some temporal recession. The recession deepens from 2A through 3A. Stage 3V (vertex) represents early HL on the crown area. Stage 4 shows further frontal HL and enlargement of the vertex balding with a solid hair band separating the front and vertex areas. In stage $4 \mathrm{~A}$, the frontal and temporal recession lines converge and resemble one smooth arch. Stage 5 shows the bald areas in the front and crown continuing to enlarge with the band of hair separating the two areas beginning to break down. In stage $5 \mathrm{~V}$ the separating band is very thin, and in 5A it disappears. Stage 6 occurs when the balding area widens, leaving a single large bald area. Stage 7 shows extensive HL with only the strip of hair remaining at the back and sides of the scalp. ${ }^{9}$

\section{SPS}

SPS was developed in 1953 by Secord and Jourand, and the Turkish reliability and validity was performed in 1989 by Hovardaoglu. This test is a 40-item inventory and every item is about an organ or a part of the body (arm, leg, face, etc..) or a function of the body (for example, sexual function). Items are scored on a five-point Likert scale ranging from 1 to 5 points. The total score may range from 40 to 200, with the higher scores indicating higher satisfaction. The cut-off point of the scale is 135 . The lower body perception group has lower points. ${ }^{10}$

\section{RSES}

RSES is a 10-item scale that measures global self-worth by measuring both positive and negative feelings about one self. The scale is believed to be uni-dimensional. All items are answered using a 4-point Likert scale ranging from strongly agree to strongly disagree. The total score may range from 0 to 30 . Scores between 15 and 25 are within the normal range; scores below 15 suggest low self-esteem. The study for the Turkish reliability and validity of this test was performed by Cuhadaroglu. ${ }^{11}$

\section{ASEX}

This scale evaluates sexual functioning in both men and women. It is a brief scale designed to assess the core elements of sexual functioning: drive, arousal, penile erection/vaginal lubrication, ability to reach orgasm, and satisfaction with orgasm. Possible total scores range from 5 to 30 , with the higher scores indicating more sexual dysfunction. Items are rated on a six-point Likert system. The study for the Turkish reliability and validity of this test was performed by Soykan. ${ }^{12}$

\section{BDI}

This is a 21-item inventory assessing symptoms of depression. Items are scored on a four-point Likert scale ranging from 0 (absent) to 3 (severe). The total score may range from 0 to 63 . Hisli developed the reliability and validity of the Turkish version of this test. Scores between 0 and 10 are within the normal range; 11 and 16 are mild depression; 17-20 are clinical depression at the border; 2130 are moderate depression; $31-40$ are severe depression, and 40-63 very serious depression. The cut-off point of the test is $17 .{ }^{13}$

\section{BAI}

This is a 21-item inventory; each item has four statements describing increasing levels of severity and questions that quantify the physiological aspect of anxiety. The total score may range from 0 to 63 . The Turkish reliability and validity of this test was performed by Ulusoy et al. Scores of 0-7 represent minimal anxiety, 8-15 mild anxiety, 16-25 moderate anxiety and 26-63 severe anxiety. The cutoff for identifying clinically relevant subthreshold anxiety is $11 .{ }^{14}$

\section{Statistical Analysis}

Statistical data were analyzed by NCSS (Number Cruncher Statistical System) 2007 Statistical Software (Utah, USA) package program. The mean, standard deviation, rate and frequency values were used for the description of statistical methods. The 
independent sample t-test was used to compare the mean scores of each psychosexual parameter according to genders. ANOVA test was used to compare of mean scores in both Ludwig and Norwood subgroups within itself, and Tukey's multiple comparison test was used to compare variances between subgroups, as a whole, for each psychosexual parameter. The SPS, RSES, ASEX, BDI and BAI scores were used as quantitative variables, whereas demographic characteristics, disease duration, and stages of Norwood and Ludwig HL scales were used as qualitative variables. Kolmogorov-Smirnov and Shapiro-Wilk tests were used to detect normalities of psychological test results. All association testing was conducted assuming a 5\% significance level. A p value $<0.05$ was considered statistically significant.

\section{RESULTS}

Demographics, disease durations, and distribution of subjects according to sex-patterned alopecia scales

The sociodemographic findings, disease durations, and the distribution of patients according to Norwood and Ludwig scales are shown in table 1 . The age range of males was 15-59, while the range was 15-63 for female patients. The mean age of the total subjects was $24.87 \pm 8.28$. The mean age of the females $(31.77 \pm 11.18)$ was significantly higher than the males $(23.16 \pm 6.34),(\mathrm{p}=0.0001)$. Most of the male $(\mathrm{n}=282$, $99.65 \%)$ and female patients $(n=64,91.4 \%)$ were under the age of 50 . The minimum and maximum disease durations were 3 months and 5 years, and the mean duration was 1-3 years. In females, the distributions of Ludwig subgroups were 45 (64.3\%) in subgroup 2, 19 (27.1\%) in subgroup 3, and six (8.6\%) in subgroup 1. In males, only Norwood $2,2 \mathrm{~A}, 3,3 \mathrm{~A}, 3 \mathrm{~V}, 4$ and $4 \mathrm{~A}$ subgroups were detected. The distributions of the males according to these subgroups in descending order were 96 (33.9\%) in subgroup 2A, 61(21.6\%) in subgroup 3, 44 (15.5\%) in subgroup 2, $31(11.0 \%)$ in subgroup 3A, 21 (7.4\%) in subgroup 3V, 19 (6.7\%) in subgroup 4 , and $11(4 \%)$ in subgroup $4 \mathrm{~A}$.

Comparison of the values obtained from psychological tests according to genders

The psychological measurements of the patients according to genders are shown in table 2 . The mean values for SPS and RSES in females were significantly lower, and the values for ASEX, BDI and BAI were significantly higher than in males (each at $\mathrm{p}=0.0001$ ).

Comparisons of Ludwig and Norwood subgroups within themselves and their multiple comparisons

In the comparison of the mean values of the Ludwig subgroups in females, significant differences were detected only for ASEX, BDI and BAI scales (Table 3). In the multiple comparison tests, the mean values of the Ludwig 3 were significantly higher than those of Ludwig 1 and 2 for ASEX and for BDI, while the mean value of Ludwig 3 was significantly higher than Ludwig 1 for BAI (Table 4). In males, between the mean values in the Norwood subgroups, there were significant differences for all five scales (Table 5). Because the scores of BDI and BAI tended to be asymmetrical, the normality of their distributions were checked with Kolmogorov-Smirnov and Shapiro-Wilk tests. Since the results of these tests for BDI and BAI variables were 0.947 and 0.951 , respectively, the distributions of the tests were accepted as symmetric, with a confidence of $95 \%$. In the multiple comparison tests of Norwood subgroups, significant differences were also obtained. SP values in Norwood 2 and 2A were higher than in $3 \mathrm{~A}, 3 \mathrm{~V}, 4$ and $4 \mathrm{~A}$, while $\mathrm{SE}$ values in $2 \mathrm{~A}$ was higher than in 3 and 4 . The values regarding S-Exp in 2 and $2 \mathrm{~A}$ were lower than in 3 , $3 \mathrm{~A}, 3 \mathrm{~V}, 4$ and $4 \mathrm{~A}$, while in 3 and $3 \mathrm{~A}$ were lower than in 4 and $4 \mathrm{~A}$. DEP was lower in $2 \mathrm{~A}$ than in $3,3 \mathrm{~A}$, and $3 \mathrm{~V}$, while it was lower in $2 \mathrm{~A}$ than 4A. ANX was lower in 2A than in 4 and $4 \mathrm{~A}$ (Table 6).

TABLE 1: Demographic characteristics, disease duration, and

distribution of Norwood and Ludwig subgroups according to HL stages

\begin{tabular}{|c|c|c|c|}
\hline \multicolumn{2}{|c|}{ Demographic and Clinical Variables } & $\mathbf{n}$ & $\%$ \\
\hline \multirow{4}{*}{ Age groups } & $15-25$ & 231 & 65.44 \\
\hline & $26-35$ & 86 & 24.36 \\
\hline & $36-45$ & 26 & 7.37 \\
\hline & $>46$ & 10 & 2.83 \\
\hline \multirow{2}{*}{ Sex } & Male & 283 & 80.17 \\
\hline & Female & 70 & 19.83 \\
\hline \multirow{3}{*}{$\begin{array}{l}\text { Marital } \\
\text { status }\end{array}$} & Single & 236 & 66.90 \\
\hline & Married & 117 & 33.10 \\
\hline & Elementary school & 49 & 13.90 \\
\hline \multirow{3}{*}{ Education } & High school & 147 & 41.60 \\
\hline & Secondary school & 128 & 36.30 \\
\hline & University & 29 & 8.20 \\
\hline \multirow{3}{*}{ Income } & Low $(<500 \$)$ & 126 & 35.69 \\
\hline & Middle (500-1000\$) & 163 & 46.18 \\
\hline & High $(>1000 \$)$ & 64 & 18.13 \\
\hline \multirow{5}{*}{ Profession } & Unemployed & 26 & 7.37 \\
\hline & Housewife & 43 & 12.18 \\
\hline & Employee & 72 & 20.40 \\
\hline & Public servant & 54 & 15.30 \\
\hline & Self-employment & 158 & 44.76 \\
\hline \multirow{4}{*}{ Disease duration } & 3-6 months & 21 & 5.95 \\
\hline & 6-12 months & 105 & 29.75 \\
\hline & $1-3$ years & 147 & 41.64 \\
\hline & $>3$ year & 80 & 22.66 \\
\hline \multirow{7}{*}{ Norwood stages } & Norwood 2 & 44 & 15.5 \\
\hline & Norwood 2A & 96 & 33.9 \\
\hline & Norwood 3 & 61 & 21.6 \\
\hline & Norwood 3A & 31 & 11.0 \\
\hline & Norwood 3V & 21 & 7.4 \\
\hline & Norwood 4 & 19 & 6.7 \\
\hline & Norwood 4A & 11 & 4 \\
\hline \multirow{3}{*}{ Ludwig stages } & Ludwig 1 & 6 & 8.6 \\
\hline & Ludwig 2 & 45 & 64.3 \\
\hline & Ludwig 3 & 19 & 27.1 \\
\hline
\end{tabular}

TABLE 2 : Comparison of mean values of all psychological measurements according to gender

\begin{tabular}{lccc}
$\begin{array}{l}\text { Psychological } \\
\text { measurements }\end{array}$ & $\begin{array}{c}\text { Male } \mathbf{n}=\mathbf{2 8 3} \\
(\mathbf{m e a n} \pm \text { SD) }\end{array}$ & $\begin{array}{c}\text { Female } \mathbf{n}=\mathbf{7 0} \\
(\mathbf{m e a n} \pm \text { SD) }\end{array}$ & p value \\
\hline SPS & $134.92 \pm 26.81$ & $104.4 \pm 17.98$ & 0.0001 \\
RSES & $15.76 \pm 5.33$ & $11.57 \pm 2.88$ & 0.0001 \\
ASEX & $17.52 \pm 4.41$ & $22.24 \pm 3.3$ & 0.0001 \\
BDI & $8.82 \pm 5.07$ & $14.74 \pm 4.44$ & 0.0001 \\
BAI & $5.95 \pm 3.83$ & $11.93 \pm 4.85$ & 0.0001 \\
\hline
\end{tabular}


TABLE 3: Comparison of mean values of all psychological measurements according to the Ludwig subgroups

\begin{tabular}{lcccc}
$\begin{array}{l}\text { Psychological } \\
\text { measurements }\end{array}$ & $\begin{array}{c}\text { Ludwig 1 } \\
\mathbf{n}=\mathbf{6} \\
(\mathbf{m e a n} \pm \text { SD) }\end{array}$ & $\begin{array}{c}\text { Ludwig 2 } \\
\mathbf{n}=\mathbf{4 5} \\
(\mathbf{m e a n} \pm \text { SD) }\end{array}$ & $\begin{array}{c}\text { Ludwig 3 } \\
\mathbf{n = 1 9} \\
(\mathbf{m e a n} \pm \text { SD) }\end{array}$ & $\begin{array}{c}\mathbf{p} \\
\text { value }\end{array}$ \\
\hline SPS & $111 \pm 19.6$ & $106.36 \pm 19.21$ & $97.68 \pm 12.63$ & 0.136 \\
RSES & $12.67 \pm 2.73$ & $11.78 \pm 3.23$ & $10.74 \pm 1.7$ & 0.263 \\
ASEX & $18.83 \pm 2.14$ & $21.8 \pm 3.17$ & $24.37 \pm 2.61$ & 0.0001 \\
BDI & $13.33 \pm 2.66$ & $14 \pm 5.06$ & $16.95 \pm 1.96$ & 0.036 \\
BAI & $9.17 \pm 5.38$ & $11.42 \pm 4.87$ & $14.01 \pm 4.04$ & 0.047 \\
\hline
\end{tabular}

TABLE 4: Multiple comparisons of mean values of ASEX, BDI and BAI, according to Ludwig subgroups

\begin{tabular}{llcc} 
Stages & ASEX & BDI & BAI \\
\hline Ludwig 1 / Ludwig 2 & 0.062 & 0.932 & 0.516 \\
Ludwig 1 / Ludwig 3 & 0.0001 & 0.048 & 0.048 \\
Ludwig 2 / Ludwig 3 & 0.006 & 0.038 & 0.120
\end{tabular}

\begin{tabular}{|c|c|c|c|c|c|c|}
\hline Clinical Stages & $\mathbf{N}$ & SPS & RSES & ASEX & BDI & BAI \\
\hline Norwood 2 & 44 & $145.07 \pm 28.08$ & $15.98 \pm 4.59$ & $15.84 \pm 4.19$ & $8.18 \pm 5.38$ & $6.11 \pm 4.4$ \\
\hline Norwood 2A & 96 & $142.96 \pm 26.09$ & $17.71 \pm 5.33$ & $15.14 \pm 4.03$ & $6.84 \pm 4.44$ & $4.9 \pm 3.65$ \\
\hline Norwood 3 & 61 & $131.97 \pm 28.18$ & $14.98 \pm 5.31$ & $18.23 \pm 3.24$ & $10.07 \pm 5.16$ & $6.05 \pm 3.63$ \\
\hline Norwood 3A & 31 & $125.84 \pm 20.24$ & $13.23 \pm 4.46$ & $19.06 \pm 3.38$ & $10.81 \pm 4.67$ & $6.94 \pm 3.86$ \\
\hline Norwood 3V & 21 & $126.14 \pm 22.02$ & $16.1 \pm 5.6$ & $20.1 \pm 2.59$ & $10.19 \pm 4.24$ & $6.29 \pm 2.7$ \\
\hline Norwood 4 & 19 & $116.79 \pm 18.38$ & $12.16 \pm 4.5$ & $22.63 \pm 3.76$ & $9.84 \pm 5.43$ & $7.53 \pm 3.73$ \\
\hline Norwood 4A & 11 & $114.18 \pm 14.25$ & $14.82 \pm 5.29$ & $23.09 \pm 2.55$ & $11.64 \pm 4.88$ & $7.73 \pm 4.25$ \\
\hline$p$ value & & 0.0001 & 0.0001 & 0.0001 & 0.0001 & 0.017 \\
\hline
\end{tabular}

TABLE 6: Multiple comparisons of mean values of all psychological measurements according to Norwood subgroups

\begin{tabular}{|c|c|c|c|c|c|}
\hline Clinical Stages & SPS & RSES & ASEX & BDI & BAI \\
\hline Norwood 2/2A & 0.999 & 0.504 & 0.941 & 0.735 & 0.564 \\
\hline Norwood $2 / 3$ & 0.124 & 0.957 & 0.019 & 0.440 & 0.999 \\
\hline Norwood 2/3A & 0.022 & 0.246 & 0.004 & 0.244 & 0.967 \\
\hline Norwood 2/3V & 0.045 & 0.999 & 0.0001 & 0.707 & 0.999 \\
\hline Norwood 2/4 & 0.001 & 0.094 & 0.0001 & 0.875 & 0.819 \\
\hline Norwood 2/4A & 0.006 & 0.994 & 0.0001 & 0.348 & 0.864 \\
\hline Norwood 2A/3 & 0.114 & 0.021 & 0.0001 & 0.001 & 0.501 \\
\hline Norwood 2A/3A & 0.02 & 0.001 & 0.0001 & 0.002 & 0.123 \\
\hline Norwood 2A/3V & 0.047 & 0.845 & 0.0001 & 0.047 & 0.725 \\
\hline Norwood 2A / 4 & 0.001 & 0.0001 & 0.0001 & 0.177 & 0.043 \\
\hline Norwood 2A / 4A & 0.007 & 0.561 & 0.0001 & 0.034 & 0.048 \\
\hline Norwood 3/3A & 0.928 & 0.705 & 0.947 & 0.993 & 0.937 \\
\hline Norwood 3/3V & 0.971 & 0.978 & 0.413 & 0.999 & 0.999 \\
\hline Norwood $3 / 4$ & 0.255 & 0.349 & 0,0001 & 0.999 & 0.748 \\
\hline Norwood 3/4A & 0.328 & 0.999 & 0.001 & 0.956 & 0.822 \\
\hline Norwood 3A/3V & 0.999 & 0.421 & 0.955 & 0.999 & 0.996 \\
\hline Norwood 3A/4 & 0.882 & 0.991 & 0.017 & 0.993 & 0.998 \\
\hline Norwood 3A/4A & 0.845 & 0.974 & 0.032 & 0.999 & 0.997 \\
\hline Norwood 3V / 4 & 0.905 & 0.186 & 0.310 & 0.999 & 0.944 \\
\hline Norwood 3V / 4A & 0.864 & 0.994 & 0.304 & 0.985 & 0.947 \\
\hline Norwood 4/4A & 0.999 & 0.813 & 0.999 & 0.959 & 0.999 \\
\hline
\end{tabular}

\section{DISCUSSION}

The prevalence of MPAA is highest in Caucasians, and reaches around $80 \%$ in men over $70 .{ }^{9,15}$ MPAA may begin shortly after puberty although in most men the onset is later. ${ }^{15}$ Most of our male patients $(99.65 \%)$ were under 50 , and the mean age was low at $23.16 \pm 6.34$. FPAA is accepted as a corresponding condition of MPAA in women. ${ }^{16}$ It usually occurs at more advanced ages, and it affects more than $50 \%$ of women over the age of 50 . Venning and Dawber found that $87 \%$ of 254 premenopausal women and $63 \%$ of 310 post- menopausal women without specific complaints of HL were in Ludwig 1-3 groups. ${ }^{17}$ Birch et al., evaluating 377 women who presented to a dermatology clinic with complaints unrelated to HL, reported a $6 \%$ incidence of the Ludwig pattern in women under the age of 50 years and $38 \%$ in women over $70 .{ }^{18}$ The increasing incidence of FPAA with advanced age was confirmed by Norwood in that $14 \%$ of 568 women under 50 reported HL compared to $26 \%$ of 438 women over $50 .{ }^{16}$ In Gan and Sinclair's study, these incidences (defined as more than stage 2 ) have been reported as $20 \%$ and $42 \%$, respectively. ${ }^{19}$ The incidence is only 3\% in ages $20-29 .{ }^{20}$ In contrast to the literature, most of our female patients $(91.43 \%)$ were under the age of 50, with a mean age of $31.77 \pm 11.18$. Most of them were in Ludwig 2 $(27.1 \%)$, and less in Ludwig $3(8.6 \%)$. Although our female population was low in count compared to literature, their mean age was still lower. On the other hand, PS-conditions that stem from a disfiguring or dermatological disorder like HL are accepted as "secondary psychiatric disorders". These include adjustment disorders with DEP, ANX, disturbance of conduct, and emotions of conduct. Associated features may be somatic and/or sexual dysfunction, feelings of guilt and/or obsession. Its effects on the patients' body image lead to the overall negative impact on their QoL. ${ }^{21}$ These psychological consequences are dependent on coping skills and on the personality traits, and the most important effect is a loss of self-confidence. This effect is enhanced by an insecurity or ambivalent attachment pattern. ${ }^{22}$ Different perceptions about HL are strongly associated with the value given to hair in society. ${ }^{21}$ Negative psychological effects of AA are more apparent among women than men, and among treatment-seeking patients. ${ }^{7}$ It has been reported that $55 \%$ of FPAA patients displayed symptoms of DEP, whereas MPAA patients were more likely to display ANX (78\%) or demonstrate aggressiveness or hostility $(22 \%) .{ }^{23}$ For a modern man, the significance of hair is almost always seen as an identity and sexual symbol. ${ }^{21}$ Although MPAA is usually accepted as a normal biological process, probable societal attitudes toward male balding vary between indifference 
and negativity. However, due to the fact that protection of youthfulness is of great value, and this concept is continuously incited by current media, HL is usually seen as a marker of aging and declining vigor and charm. ${ }^{7,15}$ Therefore, a balding man who seeks medical remedy is inevitably unhappy about his HL, and sometimes this complaint reaches the level of a body dysmorphic disorder. ${ }^{15,24}$ These patients display conflicting self-beliefs with discrepancies between the real and desired image, and have unrealistic ideals as to how they should look. ${ }^{21}$ Although the severity and frequency of MPAA in the population increase with advanced age, concerns about HL tend to be most prominent in young men who consider physical attractiveness as a vital factor. ${ }^{15}$ These concerns may lead to increased PS, lowered SE, reduced satisfaction with body image and general ANX about other difficulties related to self-worth. ${ }^{24}$ Cash has indicated that AA is typically experienced as a moderately stressful condition that decreases body image satisfaction. ${ }^{7}$ Maffei et al. reported a high frequency of personality disorders among men with MPAA. ${ }^{24}$ Alphonso et al. have stated that MPAA negatively affects patients' personal attractiveness and social life. ${ }^{25}$ Williamson et al. have also reported low SE and loss of self-confidence in MPAA patients. ${ }^{26}$ Moreover, Kranz et al. have reported that psychological distress due to HL did not depend on the age of patients or the stage of HL in MPAA. Additionally, they stated three different ways to cope: compensation, avoidance, and acceptance. According to them, compensation and avoidance were associated with high levels of distress, while acceptance was not related to distress especially in advanced stages of MPAA. ${ }^{27}$ Wells et al. have reported that increasing degrees of HL in MPAA were associated with loss of SE, DEP, introversion, neuroticism and feeling unattractive. ${ }^{28}$ In our male patients, gradually decreased values for SPS indicated that the HL might have negatively affected their SPs with the increase rate of $\mathrm{HL}$, and especially from stage 3A. For RSES, although there was a decrease from the first to last stage, because of the presence of relative increases in $2 \mathrm{~A}, 3 \mathrm{~V}$ and $4 \mathrm{~A}$, we thought that patients of these stages might have temporarily adapted to their HL. Two comparisons, between 2A and 3, and, 2A and 4 especially indicated higher negative effects for SE. Although these results were compatible with Maffei et al., Williamson et al. and Wells et al.'s statements in terms of increased tendency for lowered SE, because of the stage-related differences, our results were different from Kranz et al.'s results. For ASEX, except for between 2 and 2A, presence of gradually increased values indicated that negative sexual effects of HL began especially from stage 3. For BDI, despite presence of an increased difference between the first and last stage, most significant impact for tendency to DEP was obtained between the stages of 2A and 3. However, the absence of significant differences in the comparisons after stage 3 with all other later stages might have indicated an adaptation to HL. For BAI, presence of significant differences only between 2A and 4 , and, $2 \mathrm{~A}$ and $4 \mathrm{~A}$, indicated that a tendency to ANX might have begun after $2 \mathrm{~A}$, but might not have appeared until stage 4 . On the other hand, FPAA is often emotionally destructive condition for the women. ${ }^{4,6}$ Long, voluminous hair is thus representative of health and youthfulness. Younger women are more likely to complain of HL than those in perimenopause, and a significant association between symptoms of DEP and HL with respect to the patients particularly in the third and fourth decades of life has been shown. However, this association has been reported to not be valid for patients over 50, possibly because different conditions that trigger symptoms of DEP in this age group can simultaneously be found, as well as an increased prevalence of organic cerebral syndrome in the elderly. ${ }^{4}$ Schmidt has reported that a specific attachment vulnerability can be determined in some FPAA patients. ${ }^{29}$ Tabolli et al. have showed a higher prevalence of DEP and ANX in FPAA patients compared to patients with MPAA. They have also stated that females were more likely to adopt an "active emotional coping" strategy and less likely to have "externally oriented thinking", and more difficulty "identifying feelings" ${ }^{30}$ Schmidt et al. and Cash have reported that FPAA patients had lower SE, higher emotional distress and higher social ANX compared to females with normal hair., ${ }^{4,31}$ Maffei et al. have suggested that HL and psychiatric disorders like DEP, could often be found together in FPAA patients. ${ }^{24}$ Contrarily, Hirsso et al. have specified that the presence of DEP was not significantly higher in FPAA patients compared to women having normal hair. ${ }^{32}$ In our subjects, due to the absence of any significant difference between the Ludwig stages for SP and SE, we evaluated that HL did not differently affect women's SP and SE at any stage. Contrarily, the high scores of ASEX, BDI and BAI in our female patients might be related to the negative outward body image resulting from a sense of decreased physical attractiveness, sexual loss, masculinization, and being perceived as ugly by the opposite sex. These negative effects increased throughout the stages, and was the most intense in Ludwig 3. However, due to the very few numbers in Ludwig 1, we thought that these results could not be enough to make adequate comparisons. Although our work was not a prevalence study for these psychological disorders, we think that determination of the gradually increased tendencies for the negative effects of AA prior to the full development of the diseases is important to be able to provide appropriate psychological assistance to patients, at the right time. However, there is a need for further large and controlled studies to support our results.

\section{CONCLUSION}

AA may be a vital issue for some people who seek remedies for their HL due to a multitude of reasons. For successfully managing this process, it is very important to know which patient at which stage needs which kind of therapeutic approach (e.g medical, surgical and/or psychotherapy ). Our findings show that AA patients of both sexes have an increased tendency to develop psychosexual disorders as the stage of HL advances, and these impacts were found especially on S-Exp, ANX and DEP parameters in women. Therefore, we suggest that AA patients should be supported psychologically from the first consultation. $\square$ 


\section{REFERENCES}

1. Pavlovic S, Daniltchenko M, Tobin DJ, Hagen E, Hunt SP, Klapp BF, et al. Further exploring the brain-skin connection: stress worsens dermatitis via substance P-dependent neurogenic inflammation in mice. J Invest Dermatol. 2008;128:434-46.

2. Harvima IT, Nilsson G. Stress, the neuroendocrine system and mast cells: current understanding of their role in psoriasis. Expert Rev Clin Immunol. 2012;8:235-41.

3. Chu SY, Chen YJ, Tseng WC, Lin MW, Chen TJ, Hwang CY, et al. Psychiatric comorbidities in patients with alopecia areata in Taiwan: a case-control study. $\mathrm{Br}$ J Dermatol. 2012;166:525-31.

4. Schmitt JV, Ribeiro CF, Souza FH, Siqueira EB, Bebber FR. Hair loss perception and symptoms of depression in female outpatients attending a general dermatology clinic. An Bras Dermatol. 2012;87:412-7.

5. Veras AB, Rassi A, Valença AM, Nardi AE. Prevalência de transtornos depressivos e ansiosos em uma amostra ambulatorial brasileira de mulheres na menopausa. Rev Psiquiatr RS. 2006;28:130-4.

6. Katoulis AC, Christodoulou C, Liakou Al, Kouris A, Korkoliakou P, Kaloudi E, et al . Quality of life and psychosocial impact of scarring and non-scarring alopecia in women. J Dtsch Dermatol Ges. 2015;13:137-42.

7. Cash TF. The psychosocial consequences of androgenetic alopecia: a review of the research literature. Br J Dermatol. 1999:141:398-405

8. Ludwig E. Classification of the types of androgenetic alopecia (common baldness) occuring in the female sex. Br J Dermatol. 1977;97:247-54.

9. Norwood OT. Male pattern baldness: classification and incidence. South Med J. 1975;68:1359-65

10. Hovardaoğlu S.Turkish reliability and validty of self perception Inventory: Özdemir YD.The study of reliability and validity of body cathexis scale in schizophrenic and major depressive patients [thesis]. Ankara: Gazi University Institute of Social Science; 1990.

11. Cuhadaroglu F. Self esteem in adolescent [thesis]. Ankara: Hacettepe University Faculty of Medicine; 1986.

12. Soykan A. The reliability and validity of Arizona Sexual Experiences. Scale in Turkish ESRD patients undergoing hemodialysis. Int J Impot Res. 2004;16:531-4.

13. Hisli N. Reliability and validity of Beck Depression Inventory among university students. Türk Psikol Derg. Turk J Psychol. 1988;6:23:3-13.

14. Ulusoy M, Sahin N, Erkmen H. Turkish version of the Beck Anxiety Inventory: Psychometric properties. J Cogn Psychother. 1998;12:163-72.

15. Messenger A. Male Androgenetic Alopecia. In: Blume-Peytavi U, Tosti A, Whiting A, Trüeb RM, editors. Hair Growth and Disorders. Berlin Heidelberg: SpringerVerlag; 2008.p. 159-70.

16. Olsen EA. Female Pattern Hair Loss. In: Blume-Peytavi U, Tosti A, Whiting A, Trüeb RM, editors. Hair Growth and Disorders. Berlin Heidelberg: Springer-Verlag; 2008.p. $171-86$

17. Venning VA, Dawber RP. Patterned androgenic alopecia in women. J Am Acad Dermatol. 1988;18:1073-7.

18. Birch MP, Messenger JF, Messenger AG. Hair density, hair diameter and prevalence of female pattern hair loss. Br J Dermatol. 2001;144:297-304.

19. Gan DC, Sinclair RD. Prevalence of male and female pattern hair loss in Maryborough. J Investig Dermatol Symp Proc. 2005;10:184-9.

20. Levy LL, Emer JJ. Female pattern alopecia: current perspectives. Int J Womens Health. 2013;5:541-56.

21. Trüeb RM, Gieler U. Psychocutaneous Disorders of Hair and Scalp. In: BlumePeytavi U, Tosti A, Whiting A, Trüeb RM, editors. Hair Growth and Disorders. Berlin Heidelberg: Springer-Verlag; 2008.p. 407-26.

22. Poot F. Psychological consequences of chronic hair diseases. Rev Med Brux. 2004;25:A286-8.
23. Camacho FM, García-Hernández M. Psychological features of androgenetic alopecia. J Eur Acad Dermatol Venereol. 2002;16:476-80.

24. Maffei C, Fossati A, Rinaldi F, Riva E. Personality disorders and psychopathologic symptoms in patients with androgenetic alopecia. Arch Dermatol. 1994;130:868-72.

25. Alfonso M, Richter-Appelt H, Tosti A, Viera MS, García M. The psychosocial impact of hair loss among men: A multinational European study. Curr Med Res Opin. 2005:21:1829-36.

26. Williamson D, Gonzalez M, Finlay AY. The effect of hair loss on quality of life. J Eur Acad Dermatol Venereol. 2001;15:137-9.

27. Kranz D. Young men's coping with androgenetic alopecia: acceptance counts when hair gets thinner. Body Image. 2011;8:343-8.

28. Wells PA, Willmoth T, Russell RJ. Does fortune favour the bald? Psychological correlates of hair loss in males. Br J Psychol. $1995 ; 86: 337-44$

29. Schmidt S. Female alopecia: the mediating effect of attachment patterns on changes in subjective health indicators. Br J Dermatol. 2003;148:1205-11.

30. Tabolli S, Sampogna F, di Pietro C, Mannooranparampil TJ, Ribuffo M, Abeni D. Health status, coping strategies, and alexithymia in subjects with androgenetic alopecia: a questionnaire study. Am J Clin Dermatol. 2013:14:139-45.

31. Sawant N, Chikhalkar S, Mehta V, Ravi M, Madke B, Khopkar U. Androgenetic Alopecia: Quality-of-life and Associated Lifestyle Patterns. Int J Trichology. 2010:2:81-5.

32. Hirsso P, Rajala U, Laakso M, Hiltunen L, Härkönen P, Keinänen-Kiukaanniemi S. Health-related quality of life and physical well-being among a 63-year-old cohort of women with androgenetic alopecia; a Finnish population-based study. Health Qual Life Outcomes. 2005;3:49.

How to cite this article: Tas B, Kulacaoglu F, Belli H, Altuntas M. The tendency towards the development of psychosexual disorders in androgenetic alopecia according to the different stages of hair loss: a cross-sectional study. An Bras Dermatol. 2018;93(2):185-90. 